\title{
A DETERMINANT CRITERION FOR STABILITY ANALYSIS AND DESIGN OF LINEAR DISCRETE SYSTEMS
}

\author{
Ramesh Periyasamy, Manikandan Venugopal
}

Original scientific paper

Linear time invariant discrete systems can be described by constant coefficient linear difference equations. These equations can be easily transformed into the function of the complex variable by the $\mathrm{z}$ transform method. Two triangular matrices are formed with the help of the coefficients of system characteristics equation along with the minimal shifting of coefficients either left or right and elimination of coefficient method. A single square matrix is constructed by adding the two triangular matrices. The proposed method of construction of square matrix consumes less arithmetic operations like shifting and eliminating of coefficients, when compared to the construction of Square matrix by Jury's and Hurwitz matrix method. This Square matrix is used for testing the sufficient condition utilising Jury's Inner determinant procedure. Further one more necessary condition is also suggested along with Jury's conditions for stability. Illustrations are also included to show the applicability of the proposed scheme. Also an algorithm was developed for finding the design parameter $k$-value which helps to design a stable Linear Time Invariant Discrete System.

Keywords: algebraic test; discrete systems; linear time invariant systems; necessary condition; stability analysis; sufficient condition; two dimensional systems

\section{Odlučujući kriterij za analizu stabilnosti i konstruiranje linearnih diskretnih sustava}

Izvorni znanstveni članak

Linearni vremenski nepromjenljivi diskretni sustavi (Linear Time Invariant Discrete Systems) mogu se opisati jednadžbama linearne razlike konstantnog koeficijenta. Te se jednadžbe mogu lako pretvoriti u funkciju složene varijable metodom z transforma. Dvije trokutaste matrice stvorene su pomoću jednadžbe karakteristika koeficijenata sustava zajedno s minimalnim pomakom koeficijenata bilo lijevo ili desno i metode eliminacije koeficijenata. Konstruirana je jedna kvadratna matrica dodavanjem dviju trokutastih matrica. Za predloženu metodu konstruiranja kvadratne matrice potrebno je manje aritmetičkih operacija poput pomicanja i eliminiranja koeficijenata u usporedbi s konstrukcijom kvadratne matrice metodom matrice Jury i Hurwitza. Ta se Kvadratna matrica koristi za testiranje dovoljnog uvjeta postupkom određivanja unutarnje determinante Jurya. Dalje se predlaže još jedan potreban uvjet uz Juryeve uvjete stabilnosti. Dodane su i ilustracije za prikaz primjene predložene scheme. Razvijen je i algoritam za pronalaženje konstrukcijskog parametra $k$-vrijednosti koja pomaže u konstrukciji stabilnog Linearnog vremenski nepromjenljivog diskretnog sustava.

Ključne riječi: algebarski test; analiza stabilnosti; diskretni sustavi; dovoljan uvjet; dvodimenzionalni sustavi; linearni vremenski nepromjenljivi sustavi; potreban uvjet

\section{Introduction}

Several previous works deal with the problem of global asymptotic stability of digital filters with high performance. The nonlinearities occur due to the implementation of the system using finite word length. In contrast, much less attention has been paid for the stability analysis of discrete time-delay systems subjected to input saturation. An optimization procedure to maximize the domain of attraction is also stated in this section. The effectiveness of the derived condition is presented through the numerical examples. The stability is the most important characteristic to be possessed by all kinds of systems. In the case of Linear Time Invariant Discrete System (LTIDS), [1, 2] represented by its characteristic equation $f(z)=0$, the absolute stability is assured if $|z|<1$ and these are many algebraic schemes available to infer this situation [3]; each method has its own merits and applications. In this paper simple and direct procedures are proposed for testing the stability of a given LTIDS. In all cases, the conditions are formulated as an LMI (linear matrix inequality) feasibility test that can be efficiently solved in polynomial time by specialized numerical solvers. Numerical examples are presented to compare and illustrate the efficiency of the proposed conditions.

\section{Literature survey}

One of the problems in the analysis of such systems is the test for stability, i.e. to determine the necessary and sufficient conditions for the roots of the system characteristic equations to lie inside the unit circle in the $\mathrm{z}$ plane. These tests involve both graphical procedures such as Nyquist locus, Bode diagrams, and the Root locus and analytical methods such as Schur-Cohn or RouthsHurwitz criterion. Jury [3] studied the stability of the linear discrete systems and also conducted the test that yields the necessary and sufficient conditions for a real polynomial in the variable and shows that for the test of a fourth order system only a third order determinant is required and for the fifth order, one second order and one fourth order determinants are required. Jury [6] again performed the test and revealed that the table obtained from the method will be generated without the use of the table or division. This generation is based on a simple rule which can be easily applied. Determination of stability constants and Schur-Cohn determinants was introduced by Jury [7]. Jury also determined the maximum root within the unit circle, if the system is stable. Jury [8] clearly gives the alternate coefficients constraints for stability tests and also for determining the roots inside the unit circle. The extension of the use of these constraints for determining the number of roots on and outside the unit circle is worthwhile for future investigations. Jury and Anderson [9] postulated the requirement of the magnitude ratio of the frequency responses of the model 
and revealed that the original system deviates the least of various frequencies. Mullis and Roberts [10] discussed the use of mixed first response and auto correlation sequences. The discussion encompasses a number of techniques and algorithms. Jury [11] postulated the historical background to the Routh stability theorems and their relationships to other similar results and the stability of the 2-D polynomials and other related problems. A new property of the denominator polynomial of the transfer function of a stable discrete system was postulated by Szcupak, Mitra and Jury [11, 12]. A criterion was developed with the Routh array by Chen and Tsay [2] for the binomial product expansion and it establishes an inner product formula for evaluating the coefficients of the polynomial. Maroulas and Barnett [13] determined the arbitrary basis of orthogonal polynomials without converting polynomial into power form. Bistriz [1], Bistritz [14] and Jury [15] presented a new stability testing table for discrete linear system and revealed that it requires for a discrete system polynomials about half the number of entries and arithmetic operations that is needed in the previous Jury Marden-Criterion. Jury [16], Jury and Mansour [17] defined Analog, Counterpart, and Equivalent criteria between discrete and continuous systems. Polynomial with real coefficient to the unit circle and the importance of the degree of complexity was discussed in Kamat and Zwass [18], Jury [16]. BIBO stability of 1-D and multidimensional shift varying discrete systems was analyzed by Bauer and Jury [19]. A new method of Schur invariance property and allowable variation in the associated parameters obtained via evaluating allowable variation with some corner points were mooted by Katbab et al. [20]. Stability of a linear transfer function as fundamental and implementing the use of the Fast Fourier transform was done by Stathaki and Constantinides [21]. Bistriz [22] postulated a bivariate polynomial that does not vanish in the product of the closed exterior of the unit-circle and was developed from the Jury's modified stability test. A new technique was presented by Bistriz [23] showing that several algebraic procedures to test a bivariate polynomial are continuous discrete and stable. Stability constraints that are enough to maintain the stability of a system when some parameters are perturbed from a nominal stable setting was revealed by Bistriz [24]. Inners of square matrix were introduced by Jury [5] and revealed that for the necessary and sufficient conditions for the roots of real polynomial to be distinct and should lie in the real axis, and need to be distinct and on the imaginary axis in the complex plane. Bose and Jury [25] had tested for positive definiteness of an arbitrary form and were expressed in terms of an inner algorithm for computational aspects. A new formulation of the critical constraints for stability that limits the A matrix and its bialternate product was discussed by Jury and Gutman [4].

\section{Proposed method}

We may write form the characteristic equation $[6,8]$ of a LTIDS can be written as

$f(z)=a_{n} z^{n}+a_{n-1} z^{n-1}+\cdots \ldots \ldots+a_{0}=0$ where $a_{i}$ are the coefficients and $n$ is the degree of $f(z)=$ 0 .

The Eq. (1) is written as the following Eq. (2)

$f(z)=z^{n}+\left(\frac{a_{n-1}}{a_{n}}\right) z^{n-1}+\ldots \ldots \ldots+\left(\frac{a_{0}}{a_{n}}\right)=0$

From the theory of equations, the above can be written in Eq. (3) as

$f(z)=z^{n}-($ sum of the roots $) z^{n-1}+$

$+\left(\right.$ sum of the product of 2 - roots taken at time) $z^{n-2}-$

- (sum of the product of 3 -roots taken at time) $z^{n-3}+$

$+\cdots+($ product of all the $n-$ roots $)=0$.

\subsection{Necessary conditions}

If all the roots line with in the unit circle $[14,18]$ then the following Eqs. (4) and (5) are formed using the Eq. (3).

(i) The magnitude of each coefficient of

$z^{n-1}, z^{n-2}, z^{n-3}, \ldots z^{n-k+1}$

where, $k=2,3,4, \ldots, n$, should be less than $n$ and

(ii) The product of all n-roots

$\left|\frac{a_{0}}{a_{n}}\right|<1$

\subsection{Sufficient test}

From the coefficients of Eq. (1), the two triangular matrices are formed in Eqs. (6) and (7) as follows:

$$
\boldsymbol{M}_{1}=\left(\begin{array}{ccccc}
a_{n} & a_{n-1} & a_{n-2} & \ldots & a_{0} \\
0 & a_{n} & a_{n-1} & \ldots & . \\
0 & 0 & a_{n} & \ldots & . \\
0 & 0 & 0 & a_{n} & . \\
. & . & . & \ldots & . \\
. & . & . & \ldots & . \\
. & . & . & \ldots & a_{n}
\end{array}\right)
$$

and

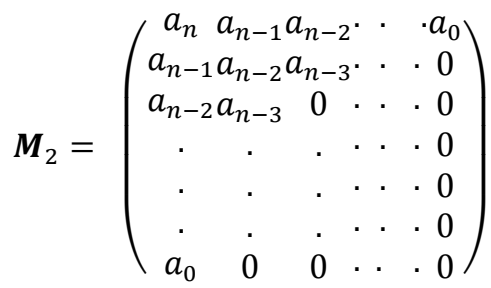

The operations are simple compared to the method used in [5]. The first rows of the matrices $\boldsymbol{M}_{1}$ and $\boldsymbol{M}_{2}$ have all the coefficients in the characteristic equation. The second row of the matrix $\boldsymbol{M}_{1}$ is one shift right the first row, insert a 0 in first and at the end eliminates $a_{0}$. Similarly the second row of the matrix $\boldsymbol{M}_{2}$ is one shift left the first row, insert a 0 at the end and eliminates the first element $a_{n}$. The third row of the matrix $\boldsymbol{M}_{1}$ is two shifts right the first row, insert two 0's in first and at the end eliminate $a_{1}$ and $a_{2}$. Similarly the third row of the matrix 
$\boldsymbol{M}_{2}$ is two shifts left the first row, insert two 0's at the end and eliminate the two elements $a_{n}$ and $a_{n-1}$. Similarly the two triangular matrices with order $(n+1) \times(n+1)$ have formed. The simple shift and elimination operation are involved in the formation of two triangular matrices.

Adding $\boldsymbol{M}_{1}$ and $\boldsymbol{M}_{2}$ a single square matrix is constructed with the Eq. (8),

$$
\begin{aligned}
& \boldsymbol{H}_{n+1}=\boldsymbol{M}_{1}+\boldsymbol{M}_{2}= \\
& =\left(\begin{array}{ccccc}
2 a_{n} & 2 a_{n-1} & 2 a_{n-2} & \cdots 2 a_{0} \\
a_{n-1} a_{n}+a_{n-2} & a_{n-1}+a_{n-3} & \cdots & . \\
a_{n-2} & a_{n-3} & a_{n} & \cdots & . \\
\cdot & \cdot & \cdot & \cdots & . \\
\cdot & \cdot & . & \cdots & . \\
a_{0} & 0 & 0 & 0 . . & a_{n}
\end{array}\right) .
\end{aligned}
$$

For the given LTIDS to be stable, $H_{n+1}$ must be positive innerwise from jury [5], A square matrix $H_{n+1}$ mentioned in the equations (9) and (12) is said to be positive innerwise $[25,4,5]$, if all the determinants mentioned in the equations (10), (11), (13) and (14) starting with the centre element and moving outwards up to the entire matrix are positive. For instance if,

$$
\boldsymbol{H}_{4}=\left[\begin{array}{c:ccc}
b_{1} & b_{2} & b_{3} & b_{4} \\
c_{1} & c_{2} & c_{3} & c_{4} \\
d_{1} & d_{2} & d_{3} & d_{4} \\
\hdashline e_{1} & e_{2} & e_{3} & e_{4}
\end{array}\right]
$$

then

$\nabla_{2}=\left|\begin{array}{ll}\mathrm{c}_{2} & \mathrm{c}_{3} \\ \mathrm{~d}_{2} & \mathrm{~d}_{3}\end{array}\right|>0$

and $\nabla_{4}=\left|\begin{array}{llll}b_{1} & b_{2} & b_{3} & b_{4} \\ c_{1} & c_{2} & c_{3} & c_{4} \\ d_{1} & d_{2} & d_{3} & d_{4} \\ e_{1} & e_{2} & e_{3} & e_{4}\end{array}\right|>0$.

Suppose,

$$
H_{3}=\left[\begin{array}{ccc}
b_{1} & b_{2} & b_{3} \\
c_{1} & c_{2} & c_{3} \\
d_{1} & d_{2} & d_{3}
\end{array}\right]
$$

then,

$\nabla_{1}=\mathrm{c}_{2}>0$

$\nabla_{3}=\left|\begin{array}{lll}b_{1} & b_{2} & b_{3} \\ c_{1} & c_{2} & c_{3} \\ d_{1} & d_{2} & d_{3}\end{array}\right|>0$.

The proposed necessary and sufficient conditions [24, $3,16,7]$ from the equations (4) to (14) are applied for the following illustrations. The Proof for the above equations is discussed by Jury in [5].

\section{Illustrations}

4.1 Example 1: [10]

Consider a second order [11] LTIDS with its characteristic equation

$f(z)=a_{2} z^{2}+a_{1} z+a_{0}=0$

$f(z)=z^{2}+\left(\frac{a_{1}}{a_{2}}\right) z+\left(\frac{a_{0}}{a_{2}}\right)=0$

From part 1, the following conditions are written:

(i) $\left|\frac{a_{1}}{a_{2}}\right|<2$

(ii) $\left|\frac{a_{0}}{a_{2}}\right|<1$

Using part 2, the required matrices are constructed:

$\boldsymbol{M}_{1}=\left(\begin{array}{ccc}a_{2} & a_{1} & a_{0} \\ 0 & a_{2} & a_{1} \\ 0 & 0 & a_{2}\end{array}\right)$

$\boldsymbol{M}_{2}=\left(\begin{array}{ccc}a_{2} & a_{1} & a_{0} \\ a_{1} & a_{0} & 0 \\ a_{0} & 0 & 0\end{array}\right)$

and

$H_{3}=\left[\begin{array}{ccc}2 a_{2} & 2 a_{1} & 2 a_{0} \\ a_{1} & \left(a_{2}+a_{0}\right) & a_{1} \\ a_{0} & 0 & a_{2}\end{array}\right]$

From $\mathrm{H}_{3}$,

$\nabla_{1}=\left(a_{2}+a_{0}\right)$

and with simplification

$\nabla_{3}=\left(a_{2}-a_{0}\right)\left(a_{2}+a_{1}+a_{0}\right)\left(a_{2}-a_{1}+a_{0}\right)$

For stability, $\nabla_{3}$ gives

(i) $\left(a_{2}-a_{0}\right)>0$ (or) $\left|\frac{a_{0}}{a_{2}}\right|<1$

(ii) $\left(a_{2}+a_{1}+a_{0}\right)>0$

(iii) $\left(a_{2}-a_{1}+a_{0}\right)>0$

Adding the conditions (ii) and (iii)

(iv) $2\left(a_{2}+a_{0}\right)>0$ (or $)\left(a_{2}+a_{0}\right)>0$

This gives that

$\nabla_{1}>0$

Adding the conditions (i) and (iv), the fifth condition is

(v) $a_{2}>0$

Thus, from the proposed determinant criterion, it is ascertained that for an even order $f(z)=0$ to have roots within unit circle, if the following three conditions hold good: 
(i) $\left(a_{2}+a_{1}+a_{0}\right)=f(1)>0$

(ii) $\left(a_{2}-a_{1}+a_{0}\right)=f(-1)>0$

(iii) $\left|\frac{a_{0}}{a_{2}}\right|<1$.

\subsection{Example 2:}

For $n=1$, the characteristic equation $f(z)=a z+b=0$ can be analysed for stability which is as shown below.

The two triangular matrices are formed

$\boldsymbol{M}_{1}=\left[\begin{array}{ll}a & b \\ 0 & a\end{array}\right]$ and $\boldsymbol{M}_{2}=\left[\begin{array}{ll}a & b \\ b & 0\end{array}\right]$

The square matrices, $\boldsymbol{H}=\left[\begin{array}{cc}2 a & 2 b \\ b & a\end{array}\right]$

For stability, $\nabla_{2}=2 a^{2}-2 b^{2}>0$

$$
=2(a+b)(a-b)>0
$$

In other words,

(i) $(a+b)>0$

(ii) $(a-b)>0$ (or) $(-a+b)<0$

From the condition (ii), it can be inferred that $\left|\frac{b}{a}\right|<1$.

Thus from the above results, it can be deduced that for $z=1$ and $z=-1$

(i) $f(1)=a+b>0$

(ii) $f(-1)=-a+b<0$

(iii) $\left|\frac{b}{a}\right|<1$.

For $n=1$, the above results hold well as necessary and sufficient conditions for stability.

Note: From the examples (1) and (2) the generalised necessary conditions for stability can be formed as given below:

For $n$ is even:

(i) $f(1)>0$

(ii) $f(-1)>0$ and

(iii) $\left|\frac{a_{0}}{a_{n}}\right|<1$.

For $n$ is odd:

(i) $f(1)>0$

(ii) $f(-1)<0$ and

(iii) $\left|\frac{a_{0}}{a_{n}}\right|<1$.

\subsection{Example 3: [26]}

Consider

$f(z)=2 z^{4}+7 z^{3}+10 z^{3}+4 z+1=0$ (or)

$f(z)=z^{4}+3,5 z^{3}+5 z^{2}+2 z+0,5=0$.

From part 1, one of the proposed necessary conditions, the coefficient of $z^{2}$ is $5>4$, which violates the stability. This inspection test immediately gives the result.
Note: On the applications of $f(1)>0, f(-1)>0$ and $0,5>1$ do not give the above conclusion on instability.

For the sake of validity of the above result the part 2 steps are applied and the square matrix.

$$
\boldsymbol{H}_{5}=\left(\begin{array}{ccccc}
4 & 14 & 20 & 8 & 2 \\
7 & 12 & 11 & 11 & 4 \\
10 & 4 & 3 & 7 & 10 \\
4 & 1 & 0 & 0 & 7 \\
1 & 0 & 0 & 0 & 2
\end{array}\right)
$$

The innerwise determinants are evaluated and are written below:

$\nabla_{1}=3>0$

$\nabla_{3}=44>0$

$\nabla_{5}=-192<0$.

Since $\nabla_{5}<0$, the sufficiency condition is violated. Hence the system is unstable

\subsection{Rule based algorithm for finding Critical value of $k_{\max }$}

In the design of a digital control system, the characteristic equation is formed as

$f(z)=a_{n} z^{n}+a_{n-1} z^{n-1}+\cdots \ldots \ldots \ldots+a_{0}=0$.

The range of $k$ for the stability is estimated using the proposed necessary and sufficiency conditions along with Rule base algorithm for finding maximum critical value $k_{\max }$.

Step 1. Let take the Characteristic Polynomial is $f(z)=$ $a_{n} z^{n}+a_{n-1} z^{n-1}+\cdots \ldots \ldots \ldots+a_{0}=0$

Step 2. Find the initial values $k(1), k(2) \& k_{\text {diff }}$. From this inference, we get the range of $\mathrm{k}$ values for given system, i.e. $0<k<k_{\max }$, i.e. let take the initial values $k(1)=1, k(2)=\frac{a_{n}+a_{0}}{2}$ and $k_{\text {diff }}=0,006$.

Step 3. Find the characteristic Polynomial $f_{n}(z)$ for $k(1)$ and $k(2)$

Step 4. Apply the necessary and sufficient test using the equations 4 to 14

Step 5. If the sufficient conditions are satisfied for the value $k(t)$ in all inner determinants, i.e., if $n$ is odd, then find inners $\Delta_{1}, \Delta_{3}, \Delta_{5}, \Delta_{7} \cdots$ and all inners should be greater than 0 (or) if $n$ is an odd, then find inners $\Delta_{2}, \Delta_{4}, \Delta_{6}, \Delta_{8} \cdots$ and all inners should be greater than 0 along with the condition $k_{\text {diff }}>0,005$, then assign $k(t+1)=\frac{k(t)+k(t-1)}{2}$ and $k_{\mathrm{cr}}=k(t)$, if the conditions are not satisfied for any one determinant and $k_{\text {diff }}>0,005$, then terminate the calculation of higher inner determinants and assign 
$k(t+1)=\frac{k(t)+k(t-1)+k(t-2)}{3}$,

calculate

$k_{\text {diff }}=k(x+1)-k_{\text {cr }}$ where $t=t+1$ for next iteration.

Step 6. If $k_{\text {diff }}<0,005$, find the value of $k(t+1)=\frac{k(t+1)+k_{\mathrm{cr}}}{2}$.

Step 7. Repeat the steps 5 to 7 until the condition $k(t)=k(t-1)=k(t+1)$ is satisfied

Step 8. Finally get the critical value $k_{\mathrm{cr}}$, i.e. the design parameter $0<k_{\max }<k_{\mathrm{cr}}$.

\subsection{Example 4: [27]}

For example, in the design of a digital control system, the characteristic equation is formed as

$f(z)=z^{4}-1,368 z^{3}+A z^{2}+B z+C=0$

where $A=0,368+0,223 k ; B=0,3974 k ; C=0,0123 k$; and $k$ is a design parameter.
The range of $k$ for the stability is estimated using the proposed necessary and sufficiency conditions along with the rule based algorithm. The proposed square matrix is constructed for the given characteristic equation:

$$
\boldsymbol{H}_{5}=\left[\begin{array}{ccccc}
2 & -2,736 & -2 A & 2 B & 2 C \\
-1,368 & (1+A) & (-1,368+B) & (A+C) & B \\
A & B & (1+C) & -1,368 & A \\
B & C & 0 & 1 & -1,368 \\
C & 0 & 0 & 0 & 1
\end{array}\right]
$$

For a final choice of $k=0,69888$, the inner wise determinants are evaluated as:

$$
\begin{aligned}
& \nabla_{1}=1,00860 \\
& \nabla_{3}=1,84796 \\
& \nabla_{5}=0,00003 .
\end{aligned}
$$

Thus the range for $\mathrm{k}$ can be fixed as $0 \leq k \leq 0,69888$ for

\begin{tabular}{|c|c|c|c|c|c|c|c|c|c|}
\hline$K$ & $A$ & $B$ & $C$ & $\Delta_{1}$ & $\Delta_{3}$ & $\Delta_{5}$ & $\begin{array}{c}\text { Stable/ } \\
\text { Unstable }\end{array}$ & $K_{\text {difference }}$ & $K_{\text {critical }}$ \\
\hline 1,00000 & 0,59100 & 0,39740 & 0,01230 & 1,01230 & 2,00511 & $-1,04314$ & Unstable & 0,00600 & 1,00000 \\
\hline 0,50615 & 0,48087 & 0,20114 & 0,00623 & 1,00623 & 1,73168 & 0,32270 & Stable & 0,00600 & 0,50615 \\
\hline 0,75307 & 0,53594 & 0,29927 & 0,00926 & 1,00926 & 1,87845 & $-0,13824$ & Unstable & 0,00600 & 0,50615 \\
\hline 0,75307 & 0,53594 & 0,29927 & 0,00926 & 1,00926 & 1,87845 & $-0,13824$ & Unstable & 0,16462 & 0,50615 \\
\hline 0,67077 & 0,51758 & 0,26656 & 0,00825 & 1,00825 & 1,83176 & 0,06343 & Stable & 0,16462 & 0,67077 \\
\hline 0,71192 & 0,52676 & 0,28292 & 0,00876 & 1,00876 & 1,85538 & $-0,03129$ & Unstable & 0,04115 & 0,67077 \\
\hline 0,71192 & 0,52676 & 0,28292 & 0,00876 & 1,00876 & 1,85538 & $-0,03129$ & Unstable & 0,02744 & 0,67077 \\
\hline 0,69820 & 0,52370 & 0,27747 & 0,00859 & 1,00859 & 1,84757 & 0,00163 & Stable & 0,02744 & 0,69820 \\
\hline 0,70506 & 0,52523 & 0,28019 & 0,00867 & 1,00867 & 1,85149 & $-0,01466$ & Unstable & 0,00686 & 0,69820 \\
\hline 0,70506 & 0,52523 & 0,28019 & 0,00867 & 1,00867 & 1,85149 & $-0,01466$ & Unstable & 0,00686 & 0,69820 \\
\hline 0,70278 & 0,52472 & 0,27928 & 0,00864 & 1,00864 & 1,85018 & $-0,00919$ & Unstable & 0,00457 & 0,69820 \\
\hline 0,70049 & 0,52421 & 0,27837 & 0,00862 & 1,00862 & 1,84888 & $-0,00376$ & Unstable & 0,00457 & 0,69820 \\
\hline 0,70049 & 0,52421 & 0,27837 & 0,00862 & 1,00862 & 1,84888 & $-0,00376$ & Unstable & 0,00457 & 0,69820 \\
\hline 0,69935 & 0,52395 & 0,27792 & 0,00860 & 1,00860 & 1,84823 & $-0,00106$ & Unstable & 0,00457 & 0,69820 \\
\hline 0,69935 & 0,52395 & 0,27792 & 0,00860 & 1,00860 & 1,84823 & $-0,00106$ & Unstable & 0,00457 & 0,69820 \\
\hline 0,69877 & 0,52383 & 0,27769 & 0,00859 & 1,00859 & 1,84790 & 0,00029 & Stable & 0,00457 & 0,69877 \\
\hline 0,69906 & 0,52389 & 0,27781 & 0,00860 & 1,00860 & 1,84806 & $-0,00039$ & Unstable & 0,00457 & 0,69877 \\
\hline 0,69892 & 0,52386 & 0,27775 & 0,00860 & 1,00860 & 1,84798 & $-0,00005$ & Unstable & 0,00457 & 0,69877 \\
\hline 0,69892 & 0,52386 & 0,27775 & 0,00860 & 1,00860 & 1,84798 & $-0,00005$ & Unstable & 0,00457 & 0,69877 \\
\hline 0,69885 & 0,52384 & 0,27772 & 0,00860 & 1,00860 & 1,84794 & 0,00012 & Stable & 0,00457 & 0,69885 \\
\hline 0,69888 & 0,52385 & 0,27774 & 0,00860 & 1,00860 & 1,84796 & 0,00003 & Stable & 0,00457 & 0,69888 \\
\hline 0,69888 & 0,52385 & 0,27774 & 0,00860 & 1,00860 & 1,84796 & 0,00003 & Stable & $\mathbf{0 , 0 0 4 5 7}$ & 0,69888 \\
\hline
\end{tabular}
the stability. The proposed scheme's results are better than those obtained through root-locus scheme of Jury.

Table 1 For different choice of $k$ values, the values of $A, B, C, \Delta_{1}, \Delta_{3}$ and $\Delta_{5}$

\section{Conclusion}

Mathematically, a 2D discrete system is represented by a set of difference equations with two space coordinates. The proposed necessary and sufficient conditions are applied to three illustrative examples. Examples 1, 2 and 5 included the design of parameters while Example 3 deals with unstable system. The presented algebraic procedure is direct and easy to apply for the investigation of stability of Linear Time Invariant Discrete Systems. The computational capability involved in the proposed scheme is better than that possessed by Jury and Bistritz methods. Also a rule based algorithm was developed for finding the design parameter $k_{\max }$ value which helps to design a stable LTI Discrete System.

\section{$6 \quad$ References}

[1] Bistriz, Y. A new stability test for linear discrete systems in a table form. // IEEE Trans. on Circuits \& Sys. 30, 12(1983), pp. 917-919. DOI: 10.1109/TCS.1983.1085318

[2] Chen, C. F.; Tsay, Y. T. A new formula for the discretetime system stability test. // in Proc. of the IEEE. 65, 8(1977), pp. 1200-1202.

[3] Jury, E. I. Notes on the stability criterion for linear discrete systems. // IRE Tran. on Auto. Control. 6, 3(1961), pp. 342-343. DOI: 10.1109/TAC.1961.1105201 
[4] Jury, E. I.; Gutman, S. On the stability of the A matrix inside the unit circle. // IEEE Trans. on Auto. Control. (1985), pp. 533-535.

[5] Jury, E. I. Inners Approach to some problems of system Theory. // IEEE Trans. on Auto. Control. AC-16, 3(1971), pp. 233-240. DOI: 10.1109/TAC.1971.1099725

[6] Jury, E. I. A simplified stability criterion for Linear Discrete Systems. // in Proc. of the IRE. 50, 6(1962), pp. 1493-1500.

[7] Jury, E. I. On the generation of the stability constraints for linear discrete systems. // IEEE Trans. on Auto. Control. 8, 2(1963), pp.184. DOI: 10.1109/TAC.1963.1105549

[8] Jury, E. I. A modified stability table for linear discrete systems. // in Proc. of the IEEE. 53, 2(1965), pp. 184-185.

[9] Jury, E. I.; Anderson, B. D. O. Some remarks on simplified stability criteria for continuous linear systems. // IEEE Trans. on Auto. Control. 17, 3(1972), pp. 371-372. DOI: 10.1109/TAC.1972.1099990

[10] Mullis, C. T.; Roberts, R. A. The use of second-order information in the approximation of discrete-time linear systems. // IEEE Trans. on Acous. Speech \& Signal Proc. 24, 3(1976) pp. 226-238. DOI: 10.1109/TASSP.1976.1162795

[11] Jury, E. I. Stability tests for one -two- dimensional linear systems. // in Proc. of the IEEE. 124, 12(1977), pp. 12371240.

[12] Szcupak, J.; Mitra, K. S.; Jury, E. I. Some new results on discrete system stability. // IEEE Trans. on Acous., Speech \& Signal Proc. 25, 1(1977), pp. 101-102. DOI: 10.1109/TASSP.1977.1162896

[13] Maroulas, J.; Barnett, S. Zero location of discrete-time linear system polynomials with respect to an orthogonal basis. // IEEE Trans. on Auto. Control. 24, 5(1979), pp.785-787. DOI: 10.1109/TAC.1979.1102143

[14] Bistritz, Y. Zero location with respect to the unit circle of discrete-time linear systems polynomials. // in Proc. of the IEEE. 72, 9(1984), pp. 1131-1142.

[15] Jury, E. I. A Generalized test for discrete system stability. // IEEE Trans. on Acous. Speech \& Signal Proc. 33, 6(1985), pp. 1614. DOI: 10.1109/TASSP.1985.1164719

[16] Jury, E. I. A note on periodicity condition for linear discrete systems. // IEEE Trans. on Auto. Control. 30, 11(1985), pp. 1100-1101. DOI: 10.1109/TAC.1985.1103843

[17] Jury, E. I.; Mansour, M. On the terminology relationship between continuous and discrete systems criteria. // in Proc. of the IEEE. 73, 4(1985), pp. 844.

[18] Kamat, P. S.; Zwass, M. On Zero location with respect to the unit circle of discrete-time linear systems polynomials. // in Proc. of the IEEE. 73, 11(1985), pp. 1686-1687.

[19] Bauer, P. H.; Jury, E. I. BIBO stability of multidimensional (m-D) shift- invariant discrete systems. // IEEE Trans. on Auto. Control. 36, 9(1991), pp. 10571061. DOI: 10.1109/9.83537

[20] Katbab, A.; Jury, E. I.; Mansour, M. On robust Schur property of discrete- time polynomials. // IEEE Trans. on Circuits \& Sys.-I: Fundamental Theory \& Applications. 39, 6(1992), pp. 467-470. DOI: 10.1109/81.153641

[21] Stathaki, T.; Constantinides, A. G. A Digital signal processing perspective on a stability test of linear system transfer functions. // IEEE Int. Sym. on Circuits \& Sys. 4, (1997), pp. 2541-2544. DOI: 10.1109/iscas.1997.612842

[22] Bistriz, Y. A stability test for continuous-discrete bivariate polynomials. // IEEE Int. Sym. on Circuits \& Sys. 3, (2003), pp. III 682-III 685.

[23] Bistriz, Y. Immitance and telepolation-based procedures to test stability of continuous- discrete bivariate polynomials. // IEEE trans. on Circuits \& Sys. 3, (2004), pp. 293-296.

[24] Bistriz, Y. Critical stability constraints for discrete-time linear systems. // IEEE Trans. on Circuits \& Sys. II: Express Briefs. 53, 2(2006), pp. 95-99. DOI: 10.1109/TCSII.2005.856032
[25] Bose, N. K.; Jury, E. I. Inner Algorithm to Test for Positive Definiteness of Arbitrary Binary Forms. // IEEE Trans. on Auto. Control. (1975), pp. 169-170.

[26] Gopal, M. Digital control and state variable method. New Delhi: TMH, 1998, p. 65

[27] Jury, E. I. Inners and stability of dynamic systems. New York: Wiley, 1974, pp. 42-43.

\section{Authors' addresses \\ Ramesh Periyasamy, Assistant Professor, M.E.}

Anna University, University College of Engineering

Department of EEE,

Ramanathapuram, 623513 Tamilnadu, India

E-mail: rameshucermd@gmail.com

Manikandan Venugopal, Professor. Ph.D.

Coimbatore Institute of Technology

Department of EEE, Civil Aerodrome Post,

Coimbatore, 641014 Tamilnadu, India

E-mail: manikandan.cit@gmail.com 